\title{
Ebola diagnosed in doctor in New York City
}

\author{
Michael McCarthy \\ Seattle
}

A physician who recently returned to New York City after caring for people in west Africa with Ebola virus disease has tested positive for the virus, city health officials said 23 October.

"We were hoping that it didn't happen, but we were also realistic," New York's governor, Andrew M Cuomo, said in a news conference. "This is New York. People come through New York. People come through New York's airports, so we can't say this is an unexpected circumstance."

Mary Travis Bassett, the city's health commissioner, said that the physician, 33 year old Craig Spencer, had been working in an Ebola treatment unit with the international relief group Doctors Without Borders in Guinea until 12 October. He left the country for New York two days later, 14 October, traveling by way of Europe and arriving in the United States on 17 October through John F Kennedy International Airport. On arrival he was screened and showed no signs of infection, Bassett said.

Since his arrival in the US Spencer has been out in the community, jogging, bowling, and traveling by subway and taxi but had been monitoring his symptoms and taking his temperature twice a day, Bassett said.

Spencer is a physician at New York-Presbyterian Hospital/Columbia University Medical Center but has not been at work at the hospital since his return from Africa, said the hospital in a statement.

Spencer reported starting to feel tired on Tuesday 21 October, Bassett said, but otherwise felt well until the morning of Thursday 23 October, when he developed a fever. He immediately notified Doctors Without Borders, which contacted local public health authorities. Spencer was transported to New York's Bellevue Hospital by a hazardous material tactical unit (HAZ TAC) ambulance, whose emergency medical technicians were dressed in full protective gear, and he was admitted to a specially prepared isolation unit. Bellevue is one of eight facilities in New York state that have been designated as Ebola treatment centers.

Health officials believe that only three people who may be at risk of infection came into contact with Spencer: two friends and his fiancée. They will be quarantined. None has shown signs of infection. A fourth potential contact, a driver for the Uber cab service, has been contacted by public health officials but is not thought to be at risk.

"There is no reason for New Yorkers to be alarmed," said Mayor Bill de Blasio. "Ebola is an extremely hard disease to contract. It is only transmitted through contact with an infected person's blood or other bodily fluids, not through casual contact. New Yorkers who have not been exposed to an infected person's bodily fluids are not at all at risk."

The bowling alley that Spencer visited has been closed "out of an abundance of caution" and will be inspected by public health officials, health commissioner Bassett said. The risk that anyone could have contracted Ebola from Spencer while he was on the subway was essentially "nil," she said.

The US Centers of Disease Control and Prevention, which already had a team of Ebola experts in the city assessing hospital readiness, has already dispatched three members of its Ebola response team to provide additional assistance.

Spencer is the fourth person in the US in whom Ebola virus disease has been diagnosed. The first was Thomas Eric Duncan, a 42 year old Liberian national who fell ill in Dallas, Texas, shortly after arriving from west Africa, and then two nurses who cared for him at Texas Health Presbyterian Hospital Dallas, Nina Pham, 26, and Amber Vinson, 29, were infected. Duncan died of the disease 8 October after 11 days in hospital. ${ }^{1}$

Pham has been transferred to a high level biocontainment isolation unit at the National Institutes of Health Clinical Center in Bethesda, Maryland. Vinson has been transferred to a similar unit at the Emory University Hospital in Atlanta, Georgia. Both are reported to be doing well.

Cuomo said that New York health personnel had been preparing, training, and drilling for months to get ready for an Ebola case. "We're as ready as one could be," Cuomo said.

"What happened in Dallas was the exact opposite. Dallas was caught before they could prepare, before they knew what they were dealing with. New York City has learned from the Dallas experience," he said.

1 McCarthy M. Liberian man being treated for Ebola in Texas dies. BMJ 2014;349:g6145. 